\title{
ASSISTED HOUSING FOR THE ELDERLY IN MANDALUYONG CITY: A SOCIAL ENTERPRISE
}

\author{
Renilda A. Magsino ${ }^{1, a *}$, Ester T. Edralin ${ }^{2, b}$, Felecitas C. Tuazon ${ }^{3, c}$ \\ ${ }^{1}$ Faculty member in Entrepreneurial Management, College of Business, Rizal Technological \\ University, Mandaluyong City, Philippines \\ ${ }^{2}$ Head, Marketing Department, College of Business, Rizal Technological University, Mandaluyong \\ City, Philippines \\ ${ }^{3}$ Faculty member in Accountancy, College of Business, Rizal Technological University, \\ Mandaluyong City, Philippines \\ a Email address: renilda magsino@yahoo.com, bemail:retse_888@yahoo.com, \\ cemail:felecitas_tuazon@yahoo.com
}

\begin{abstract}
Keywords: senior citizens, interdisciplinary research, mixed method, assisted homes, explanatory sequential design, social enterprises
\end{abstract}

\begin{abstract}
This interdisciplinary, mixed-method research using the explanatory sequential design studied one sector of the elderly community's living condition in Mandaluyong City to determine the viability of putting up a privately-funded residential and care facility for them. Sixtynine senior citizens were surveyed by a group of $4^{\text {th }}$ year business students in 2013 for their feasibility study about an economic housing for the elderly, using a government-published questionnaire. Raw data from these instruments were, with the consent of the said students, used for this study. Analysis showed that the profile of the elderly under study matched with the local government statistics. The qualitative variables reflected the elderly's feeling of neglect and loneliness and the desire to live in a more quiet and modest but decent living facility away from their noisy and chaotic home environment. Numerous laws, bills, plans, and other government initiatives that provide assistance for the welfare of the elderly were identified and determined to be useful in providing ideas to solve the problem at hand. It was therefore concluded that a privatelyfunded facility earlier proposed under an undergraduate feasibility study was economically viable after review in the areas of marketing, technical and financial aspects and that government interference was proposed to be solicited.
\end{abstract}

\section{INTRODUCTION}

A 2011 United Nations study (Current Status, 2011) showed that "older persons in developing countries tend to live in multigenerational households though this practice has begun to decline with the changes in family structure driven by migration and other factors". This finding is consistent with the Philippine situation wherein the extended family traditionally provides care and support for their elders. However, "current realities have begun to challenge the capacity of traditional social structures to provide for their basic needs" and that "today, there are elderly citizens in our community living lives of quiet desperation". (Senate Bill 2352, Implications), filed on August 4, 2010 by Peter Alan Cayetano. The said bill, still pending in Congress manifests the sad reality faced by some sectors of the senior society.

Even before the introduction of Senate Bill 2352, there was already an existing law directing the implementation of a program providing group home/foster home for frail older persons, among others (Executive Order No. 105 dated May 16, 2002). However, this legislation is limited to the establishment of foster homes for the neglected, abused and/or homeless and disabled persons who are incapable of self-care. Since the law's mandate specifically caters to indigent old people and source of funding is left to different agencies of government without specific amounts and source, donations support most of the facilities' operating expenses. The situation in these foster homes are 
unacceptable for those who have pensions to spend but not big enough to support them if they were to live on their own. Another government initiative, Philippine Plan of Action for Senior Citizens 2012-2016 (PPASC) also supported the idea that de-institutionalization and putting up of proper health facilities are in the best interest and welfare of the elderly. Despite these initiatives and mandates, no remarkable facility has been established so far. The unmet needs of the elderly still remain a social problem to reckon with. In most cases, the children are already old themselves who, if still in good health are grand parenting and supervising the household for their own married children many of whom are employed overseas. It is therefore inconvenient, if not impossible to care for their own old parents. For lack of alternative options, it thus becomes an obligation for some senior children to take care of the old parents and at the same time looking after their grandchildren in a common home, depriving both the old parents and grandchildren the proper attention and care they need. This sad state is aggravated by the high cost of services of house helpers and prohibitive prices of residential houses that caused present day families to live in relatively small and compact houses. In some instances, elderly children are still too busy working for their own provisions. The irony of it is that the social security pensions of many senior citizens, augmented by allowances from families and government subsidies can provide for their assisted living expenses if managed well. (Bahay Pagasa, 2013, Johri M., et al 2003, The Economist, 2012). Assisted living facilities which are common in other countries thus could become an option. In China, homes for the elderly of this kind are maintained for only $\$ 250$ a month (The Economist, 2012) paid from their pensions. This is roughly equivalent to P10,000.00 a month.

This situation motivated the researchers to conduct a study on the viability of an assisted living facility for the elderly with functional limitations as proposed by a group of business students in their feasibility study (Bahay Pag-asa, 2013). Guided by the NHERA2 document, particularly Agenda $3 \& 4$, the College of Business \& Entrepreneurial Technology (CBET) of the Rizal Technological University (RTU) prepared its 2013 CBET Research Agenda identifying the area on elderly care service as its banner research output. It also offered opportunity to transfer business incubation knowledge to the local government as an extension project with the private sector as a sustainable business partner.

Heeding the task mandated under RA 9257, the Social Development Committee of the National Economic and Development Authority approved and adopted the PPASC through its Resolution No. 4, series of 2007 which it describes as being anchored on several international, regional and national mandates.

The Framework: Theory of Change inspired by Harvard Business School (2013) was drafted and shown below:

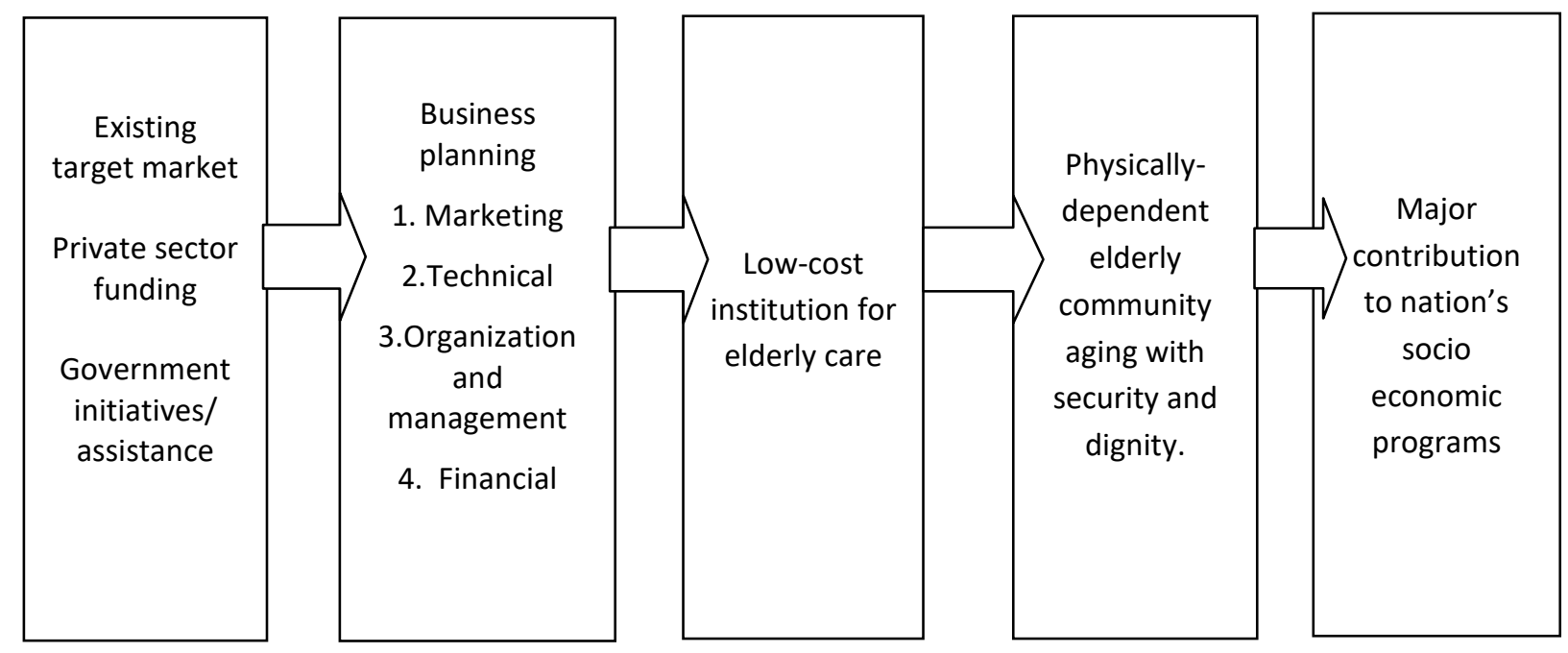


The above framework shows that having an identified target market, coupled with private funding and existing government initiatives, an economic institution for elderly care is viable.

\section{Statement of the Problem}

The research issues explored and discussed were the following:

1. Profile of senior citizens of selected Barangays in Mandaluyong City;

2. Problems/needs commonly experienced by the senior citizens as to:

2.1 Economic aspect,

2.2 Social/emotional,

2.3 Health, and

2.4 Housing;

3. Government laws and initiatives for the welfare of senior citizens:

3.1 Philippine Plan of Action for Senior Citizens (PPASC 2006-2010)

3.2 Philippine Plan of Action for Senior Citizens (PPASC 2012-2016)

3.3 Republic Act 7432. An Act to Maximize the Contribution of Senior Citizens

To Nation-Building, Grant Benefits and Special Benefits and Privileges and for Purposes.

4. Viability of an economic residential facility for selected elderly in the following aspects:

4.1 Marketing,

4.2 Financial, and

4.3 Social.

The researchers looked into this social problem from a business perspective to be able to help solve economic problems. It could accelerate generation of employment and encourage entrepreneurial spirit among the youth who are no longer interested in looking after the elderly on a familial basis but could reconsider when done on a professional or entrepreneurial level; and at the same time providing a basis for government in solving social problems on appropriate housing for the elderly with pensions or regular source of income.

The conduct of this research also served to attain the objectives of the National Higher Education Research Agenda 2 (NHERA2), issued and published by the Philippine Commission on Higher Education.

The subjects of this study do not include indigent senior citizens who are being cared for by homes for the neglected indigent elderly like the Elsie Gatches Village, Golden Acres, and other similar facilities being run by the DSWD. This study also made no attempt to investigate the reason by Senate Bill 2352 is still pending as of this writing but found the proposed law's rationale in its explanatory note very relevant to this research.

\section{METHODOLOGY}

As a mixed method research, both quantitative and qualitative approaches were applied. Dauwerse's (2012) and the Best Practices (2014) provided keystone for this methodology. A mixed method research design is a procedure for collecting, analyzing and mixing both quantitative and qualitative research and methods in a single study (Creswell, J., 2012; Fraenkel, 2012; Cooper, 2008 p. 185; Saunders, 2009 p.153; Churchill, 2012; and sagepub.).

Specifically, explanatory sequential design was deemed most appropriate. This involved collecting quantitative data first and followed up with qualitative data collection and analysis to arrive at an interpretation. (www.fischlerschool.vova.edu/ p. 26). 
As an interdisciplinary study, (www.nsf.gov/.../interdisciplinary_research, and www.cf.ac.uk/.../Tips), it allowed multiple perspectives such as social studies, economics, marketing, public policies and accounting.

Purposive sampling was used. The samples were taken from a list of senior citizens with monthly pensions which was available at the Office of Senior Citizens Affairs of the city of Mandaluyong. The personal information of the respondents taken from the filled out Senior Citizen Survey Form (SCSF), a government form available online were used to collect quantitative data from which the tables on the profiles were based. For the qualitative data, themes, which were already manifested in the accomplished SCSF were analyzed. The details were drawn from the open-ended responses and frequency tables for qualitative variables were made. (isites.harvard.edu/icb/icb.do); (Howitt 2010) and (Sagepub.com/upm). studied.

Percentages were computed from the quantitative data from the profile of the senior citizens

\section{RESULTS AND DISCUSSION}

1. The profile of the senior citizens revealed the following:

1.1 Sixty-two percent of those studied were female and $38 \%$ were male while the city-wide statistics show that $56 \%$ were female and $44 \%$ were male. Both statistics reveal that there were more female seniors than the male counterparts. This is consistent with the UN study that women tend to live longer than men (www.un.org/.../current-status-older-person). These data provided the information needed for evaluating the provisions for the services.

1.2 Eleven or $16 \%$ of those studied were below 65 years old, 33 or $48 \%$ were within the age bracket $65-69 ; 25$ or $36 \%$ were 70 years old and above. This is consistent with the city-wide statistics of Mandaluyong for 2010 . The $36 \%$ seniors who were over 70 years old (or 1,890) were the target market in determining the viability of the project.

1.3 Thirty-two percent those surveyed have college degrees or have gone to college. These data were useful in determining the appropriate activities planned for the target market.

1.4 Fifty-seven percent of the respondents have regular income from pensions and other sources: This group was considered in determining the demand for the facility in the marketing aspect.

2. The responses for the open-ended questions explained the details of the grievances and problems common to the respondents. From the document analysis (Mason, 2002, p. 103) used to interpret information gathered from already existing set of data, the following findings surfaced:

2.1 Qualitative Variables- Social/Emotional Concerns. It was found out that feeling of helplessness, worthlessness, loneliness and isolation, and neglect and rejection were the most common grievances of the respondents. These feelings must have been brought about by the fact that there were inadequate leisure and recreational activities and senior-citizen friendly environment.

2.2 Qualitative Variables- Housing Concerns. The study revealed that most of the respondents complained of overcrowded family home. One respondent verbally shared that although it is nice to be with own family, she cannot adjust to the noise of the younger members and chaotic movements in the family abode. She wished she had a place of her own to be able find peace when she feels like being alone. She however cannot deny the fact that she cannot afford a place of her own although she can afford her basic needs.

3. Government interventions that could support the proposed initiative for the establishment of private assisted living facility for the elderly in the Philippines:

a. Philippine Plan of Action for Senior Citizens (PPASC 2006-2010). The PPASC 2006-2010 is a Philippine government document formulated, through inter-agency efforts that spells out the strategies, programs, projects and activities contributing to the attainment of the Millennium 
Development Goals and the Medium Term Philippine Development Plan for the promotion of Active Ageing in the Philippines. The priority areas set were geared towards ensuring that societies and individuals age with security and dignity. Like NHERA2, PPASC 2006-2010 encourages networking as it empowers local government units to respond to the needs of the senior citizens under their jurisdictions. The document also provided the Senior Citizen Survey Form, the instrument for collecting up-to-date information from which to assess the situation of senior citizens and to make appropriate programs and projects. These forms are being made available online by the Department of Interior and Local Government to the barangays for dissemination.

b. Philippine Plan of Action for Senior Citizens 2012-2016 promotes a more effective and efficient service delivery for senior citizens. It focused on the three major areas of concern in ageing, one of which is to ensure enabling and supporting environments. This Plan observed that only government-run and NGO-operated centers, residential and group homes are subject to DSWD standards, but privately-run, for-profit nursing homes are not specifically under any government agency's particular jurisdiction. It also suggests that although the present policy is the deinstitutionalization and reintegration of the elderly to their own family environments, it appears that for extreme cases, proper health facility must be considered for the best interest and welfare for the elderly. This sets the basis for the establishment of a private living facility for the elderly.

c. Republic Act 7432, "An Act to Maximize the Contribution of Senior Citizens to Nation Building, Grant Benefits and Special Benefits and Special Privileges and for Other Purposes". This law enumerates the privileges and benefits provided to senior citizens. Sec. 5 (b) specifically states that individuals or non-governmental institutions establishing homes, residential communities or retirement villages solely for the senior citizens shall be accorded the following: realty tax holiday for the first five years starting from the first year of operation; and priority in the building and/or maintenance of provincial or municipal roads leading to the aforesaid home, residential community or retirement village. This would serve as a motivating factor for private individuals or groups to go into the senior citizen housing business.

4. Viability of an economic residential facility. The evaluation showed that the proposed assisted living facility for the older senior citizens is viable on the following grounds:

4.1 Marketing aspect. The project's target market were senior citizens who have functional limitations but have no other health problems and receiving not less than P10,000 monthly pensions, allowances and entitlements. The data readily available from the previously used instruments of the said study were used by these researchers to determine the market viability of the proposal. Based on the Mandaluyong City statistics (2010), Barangays San Jose, Malamig, Mauway, Highway Hills and Hulo which have been covered by the study, there were 82,968 population $5,400(6.5 \%)$ of which were senior citizens (60 years old and above). Of the 5,400, $35 \%$ or 1,890 were 70 years old and above. The adjusted conservative target market considered for the study was only 25 out of the 1,890 or less than one and a half percent of the computed target market.

4.2 Financial aspect. The 5-year comparative pro-forma financial analyses show that a business' payback period on a P2, 000,000.00 investment is a little over 2 years. The return on investment for the five year period would be $23.32 \%, 23.32 \%, 37.45 \%, 37.45 \%$ and $37.45 \%$, respectively. The financial study showed that investing in this kind of venture would be a sound decision.

4.3 Socio-economic aspect. As an interdisciplinary study, these researchers found that the project, aside from being financially viable, would be doing a great contribution and impact on the social and economic initiatives of government in alleviating the difficulties faced by some of the physically- challenged but financially-abled older senior citizens. 


\section{CONCLUSION AND RECOMMENDATIONS}

\section{Conclusions}

1. There exists a sector in the elderly community whose members expressed the desire to live in modest but decent homes away from the hassles and noise of own family houses. These kinds of homes can only be provided by assisted living facilities funded by private entrepreneurs applying the principle of economies of scale. This principle shows the cost advantage that arises with increased output of a product. The inverse relationship between the per-unit fixed cost and the volume produced can make collective caring for the selected elderly in a wellmanaged facility affordable. This is so because the fixed costs can be shared over the larger number of services to be rendered.

2. There are some elderly who are "living lives of quiet desperation" and that "programs for the protection and welfare of the elderly is urgent and always a priority". Grievances of the elderly have already been documented, and that what is being catered to only by the government are those who are declared indigent.

3. The government has recognized the importance of the issues at hand. This could be gleaned from the numerous laws, bills and other initiatives already enumerated above. However, the existing policies and plans bear no specific provision that could be applied to solve the problem at hand.

4. The project originally proposed in the Bahay Pag-asa 2013 feasibility study was found to be viable.

\section{Recommendations}

1. It is recommended that the city government OSCA conduct a current survey of qualified elderly who need to be housed in an assisted living facility.

2. It is also recommended that the PPASC 2012-2016 findings must be looked into. The fact that only government and NGO-run residential homes for elderly are subject to DSWD standards, entrepreneurs shy away from investing in socio-economic ventures since there are no legal nor government support to back them up. Likewise, the PPASC point of view that although the ideal setting is that the elderly must be cared for by the family, in extreme cases, proper facilities must be considered best for the elderly's welfare and interest and appropriate action be initiated.

3. Future government plans and initiatives must include provisions that would encourage the private sectors to invest in assisted living facilities for the elderly who have a modest income to support such kind of housing.

4. The result of this study is proposed to be used for an extension service under the RTU's mandate in conformity with CHED's NHERA2 objective, which is transferring business incubation knowledge to local government units and other stakeholders.

\section{References}

[1] Current Status of the Social Situation, Well-Being, Participation in Development and Rights of Older Persons Worldwide. (UN 2011).

http://www.un.org/esa/socdev/ageing/documents/publications/current-status-older-persons.pdf. Retrieved October 2014.

[2] Senate Bill 2352, $15^{\text {th }}$ Congress. Implications. Welfare and Protection Act for the Elderly of 2010.

[3] Executive Order No. 105 dated May 16, 2002. Approving and Directing the Implementation of the Program "Provision of Group Home/Foster Home for Neglected, Abandoned, Abused, Detached and Poor Older Persons and Persons with Disabilities"

[4] Philippine Plan of Action for Senior Citizens 2012-2016 
[5] Bahay Pag-asa Feasibility Study" (2013).

[6] Johri, M. etal. 2003. International experiments on integrated care for the elderly: a synthesis of the evidence. International Journal of Psychiatry. www.onlinelibrary.wiley.com/doi. Retrieved Oct. 30,2014

[7] The Economist . Caring for the Elderly: New Homes for the Old, 2012.

[8] National Higher Education Research Agenda 2 (NHERA2)

[9] Republic Act 9257. An Act Granting Additional Benefits and Privileges to Senior Citizens Amending for the Purpose RA 7432.

[10] Developing a Social Enterprise Business Plan (2013). Harvard Business School (Ret.8/14/15)

[11] Dauwerse, L. etal. Morality in the mundane: Specific needs for ethics support in elderly care. Sage Publications.2012.

[12] Best Practices for Mixed Methods Research in the Health Sciences. National Institute of Health, US Department of Health \& Human Services.

www.obssr.od.nih.gov/scientific_areas/methodology/mixed_methods_research/section1. Retrieved October, 2014.

[13] Creswell, J. Educational Research. Planning, Conducting, and Evaluating Quantitative and Qualitative Research. $4^{\text {th }}$ ed. Pearson.2012.

[14] Fraenkel, J.R., Wallen,N.E \& Hyun, H.H. How to Design and Evaluate Research in Education. McGraw-Hill.2012.

[15] Cooper, D.R. \& Schindler, P.S. Business Research Methods $10^{\text {th }}$ ed. McGraw-Hill International Edition.2008.

[16] Saunders, M., Lewis, P. \& Thornhill, A. p. 362-363). Research Methods for Business Students. Pearson. Singapore.2009.

[17] Fischler, A. Mixed Methods. Nova Southeastern University. (www.fischlerschool.nova.edu/applied-research/procedures and resources) retrieved Oct. 2014.

[18] What is Interdisciplinary Research? Cardiff University 2008. www.cf.ac.uk/.../Tips www.cf.ac.uk/.../Tips

[19] www.isites.harvard.edu/icb/icb.do

[20] Howitt, D. and Duncan Cramer. Introduction to Research Methods in Psychology $2^{\text {nd }}$ ed. Pearson Education.2010.

[21] Introduction to applied thematic analysis. Chapter 1. www.sagepub.com.upm

[22] Mason, J. Qualitative Researching $2^{\text {nd }}$ ed. Sage Publications, London. pp.71 \& 103.2002.

[23] Philippine Plan of Action for Senior Citizens (PPASC 2006-2010).. Retrieved 10/27/14

[24] Republic Act 7432. An Act to Maximize the Contribution of Senior Citizens to Nation Building, Grant Benefits and Special Privileges and for Other Purposes. 